\title{
LA PERSONA HUMANA, EL VALOR CENTRAL DE LA EDUCACIÓN
}

Saúl Gahona

Estudiante de la Carrera Filosofía y Pedagogía

Universidad Politécnica Salesiana

Es ineludible el nexo existente entre Ética y Educación, hasta el punto que no se concibe una educación como tal si no existe una orientación ética en ella. Pudiera no existir un vínculo, pero entonces la educación dejaría de ser tal. Todo quehacer educativo procura orientar su accionar desde la valoración ética que mejor garantice su propósito. Y la ética tiene como finalidad iluminar a la educación y efectivizar, mediante la misma, que el educante interiorice o descubra los valores que subyacen en él.

Pero el propósito de esta reflexión no es hacer una descripción y/o justificación de la relacionalidad entre Ética y Educación a nivel epistemológico; bástenos ver la obviedad sobre esa relación. Se pretende más bien, supuesto ese vínculo, hacer desde la filosofía una reflexión aproximativa sobre la centralidad axiológica de la persona humana ${ }^{1}$ en la educación, describiendo sus características fundamentales. Es de suponer que si la persona es el valor central de la educación, la ética será de tendencia personalista, cuyo valor, por excelencia, es la misma persona humana. 
De este modo, si la persona humana es el valor desde el que se fundamenta y estructura la ética, será, por consiguiente, este tipo de ética la que la ubicará como el valor central de la educación. Como se puede percibir, esta reflexión sobre educación trata de argumentarse desde una ética de los valores, pero con un distintivo importante: una ética desde el valor de la persona.

\section{La ética desde el valor de la persona}

Sin detenernos a discutir la legitimidad del valor y la historia de su reciente aparecimiento ${ }^{2}$ en el siglo XX, pasaremos a fundamentar a la persona como el valor central, desde el cual la ética adquiere su peculiar modo de ser.

a) El valor absoluto de la persona

Es muy notoria la marginación que sufre la persona humana en la filosofía moderna, especialmente cuando ésta logra su máxima expresión con la figura de Hegel. Desde la razón, el proyecto filosófico hegeliano adquiere un sistema de pensamiento muy bien estructurado, dentro del cual se pretende acomodar a todos los existentes. Este intento es posible, puesto que, en el pensamiento de Hegel se da una identidad entre razón y realidad, es decir, aquello que se construye racionalmente es lo que es o sucede realmente. En este sentido, la persona humana es abordada desde una lógica puramente racional, $y$, acto seguido, ignorada en su realidad existencial y marginada en su valoración personal e individual.

No en vano los filósofos de la existencia levantaron su protesta contra aquella filosofía que diluyó en un sistema de pensamiento al ser humano concreto e individual. Las incidencias políticas e ideológicas acaecidas en la historia debido a esta idea fueron nefastas. Y es allí precisa- 
mente, con la reflexión existencialista y personalista que hace el ser humano de sí mismo, donde resaltó con fuerza el valor de la persona. Se pudo experimentar que no son los sistemas de pensamiento ni las estructuras sociales generadas las que existen y sienten, sino la persona real y concreta.

En ese contexto y gracias a las reflexiones, especialmente de los personalistas, el valor de la persona humana se consagra definitivamente y logra el reconocimiento de su valor absoluto, por encima de cualquier otro proyecto. Así, la persona precisa su valor al manifestarse:

... como un ser único, irrepetible, dotado de interioridad -autoconciencia y libertad- y destinado a la comunión; es decir, es un sujeto que existe corporalmente con otros en el mundo, para realizarse con ellos en la historia, personal y comunitariamente, tomando una actitud o, lo que es lo mismo, comprometiéndose libremente frente a los valores, frente a las demás personas y, sobretodo, frente a Dios (Gastaldi, 1994: 181).

La dignidad de la persona radica en la autoconciencia y en la autodeterminación, con las cuales ésta se ubica sobre lo infrahumano y logra comunicarse con los demás. La persona elige y decide sus propios actos y es capaz de intuir y proyectar su propio destino. La persona es individuo, cuyo crecimiento se da en la relación interpersonal y social. Vive la experiencia de la autotrascendencia y para ello necesita cultivar su dimensión espiritual, con la cual cae en cuenta que su fin último sobrepasa lo puramente material. La persona es, finalmente, un fin en sí mismo y nunca un medio.

De este modo, aunque muy escuetamente, se han puesto de manifiesto algunas características fundamentales de la persona humana. Y es desde esta perspectiva que surge la objetividad y subjetividad de este valor, el mismo 
que hace de la ética una propuesta normativa humana, real, práctica y siempre actual. Todos los demás valores adquieren vida, por así decirlo, cuando se fundamentan y personalizan en la persona humana.

b) Objetividad y subjetividad del valor de la persona humana

El valor central es la persona, y es ella lo más objetivo que hay. Nadie podría negar la realidad de la experiencia humana. La existencia humana de la persona es lo más concreto, pero, a la vez, lo más subjetivo, puesto que es también su subjetividad la que acentúa la objetividad de la persona humana. Además, porque lo subjetivo hace referencia directa a su interioridad, a sus experiencias de vida únicas e irrepetibles. En esta misma dinámica, los valores en la persona son objetivos y subjetivos.

Comprendido y asumido de este modo el valor de la persona humana, se propone a ésta como el valor central de la ética, desde la cual, a su vez, se da la base y orientación para los criterios del accionar educativo.

\section{Una educación desde el valor central}

Aunque actualmente la educación en valores sea un tema que, por fuerza de su repetitividad, esté perdiendo significado, no obstante, la objetividad siempre actual y concreta de nuestra propuesta ético-educativa, nos anima a reiterar sobre esta magnífica posibilidad en la educación.

Como hemos dicho en la introducción de este breve artículo, es inevitable el nexo entre ética y educación, porque toda educación procura desplegar su quehacer educativo desde unos presupuestos éticos fundamentales, que en nuestro caso subyacen en la persona humana concreta. Existe una mutua implicación entre esta dos, tanto si la 
ética da pautas axiológicas para educar, cuanto si la educación como responsable de la formación humana, propone y desarrolla una ética al momento de educar.

Ahora bien, no siendo nuestro propósito dar recetas pedagógicas y didácticas para educar desde el criterio axiológico que hemos fundamentado, sólo nos corresponde dejar en claro a quienes han enrumbado su vida por la maravillosa y a la vez difícil tarea educativa, que toda intencionalidad educativa debe tener como indicador central a la persona. Los proyectos educativos, así como las acciones concretas de todo educador, no deben perder de vista esta orientación. Se trata de educar personas y de orientar hacia ellas todo cuanto en pro de su crecimiento se haga.

Es de vital importancia que los educadores se hayan formado con este criterio ético y educativo, porque de ello depende, que tipo de educación vayan generando. De la concepción que se tenga de la persona humana dependerá la educación que se vaya forjando. Para conocer esa concepción bastaría preguntar: "muéstrame lo que tú piensas y conoces sobre la persona humana y, yo te mostraré de antemano, que tipo de educación estás forjando" (Saavedra, 2005: 33).

Resulta importante esta propuesta ética y educativa con acentuada inspiración personalista, porque es el eje central desde el cual todo quehacer humano (educativo, laboral, económico, político, científico, etc.) caminaría para bien. La cultura como tal, por ejemplo, se vería iluminada desde esta perspectiva y se evitarían manifestaciones y acciones, que, por ser supuestamente culturales, permiten y hasta justifican el atropello de los derechos fundamentales de la persona. En lo científico esta reflexión resplandecería de inmediato, y la ciencia procuraría estar más al servicio del ser humano y no al revés. No se 
debe olvidar, como decía Rabelais, que ciencia sin conciencia, es ruina moral. En el campo educativo, como hemos visto, este criterio es decisivo.

\section{Criterio desde el cual delinear el accionar educativo}

Todo el quehacer educativo se desarrolla en torno a la valoración que se tenga sobre tal o cual aspecto de la realidad y/o de la persona. Así, este criterio será el mismo principio ordenador que se traza para establecer una adecuada jerarquía de valores. En este orden, será pertinente rescatar o descartar cualquier proyecto educativo, según construya o destruya humanamente al hombre y la mujer concretos. "Para construir aquello que suponemos tiene más valor, se necesita que sea más digno de la humanidad, más profundo en la humanidad, más humano en su calidad"3. Supuesto esto, ¿qué más debe procurar la educación como tarea suya, teniendo a la persona como el valor central?

\section{La formación de la conciencia moral}

En atención a trazar y efectivizar una educación desde y para la persona humana, es prioritario que para ello se forme la conciencia de ésta. La conciencia es en la persona ese "... testigo inmutable e intraicionable de todos los actos humanos” (Saavedra, 2005: 49). Es allí donde se debe enfatizar primero, cuando se pretende educar en valores. Actuar según nuestra conciencia implica de antemano tener una conciencia formada moralmente. Los valores no serían valorados como tales sin una conciencia moralmente educada y orientada. El docente, por ejemplo, no lograría apreciar la gravedad de su responsabilidad como educador, ni ejercería con honestidad su tarea edu- 
cativa, si su conciencia no estuviera formada moralmente. Es, por consiguiente, un serio desafío para la educación formar y orientar las conciencias de la juventud que educa.

\section{Interiorización del valor ético}

La educación, por tanto, debe asumir como tarea primordial el propiciar en los educantes la posibilidad humana de la interiorización de los valores y convertirlos en éticos. Todos los valores pueden llegar a ser valores éticos. Cuando los valores se interiorizan, se asimilan, se comen en la conciencia, se convierten en éticos. El valor es ético porque es interior, $y$, en cuanto intrínseco, obliga a la persona a actuar éticamente. Es esta la obligación ética; es decir, el valor una vez profundizado y constituido éticamente, adquiere la propiedad de la obligatoriedad, que es inevitable en la persona. Caso contrario no sería un valor ético.

Los valores religiosos, por ejemplo, si no conllevan lo ético, son una falsedad. Los valores, una vez interiorizados en la persona, son éticos, y nadie se los puede quitar, aun cuando esta se vea amenazada en su integridad.

\section{Conclusiones}

A manera de pautas y dejando el tema abierto, se concluye con las siguientes ideas:

Teniendo claros los criterios éticos desde los cuales educar, queda, para su real efectivización, que la educación busque los criterios pedagógicos pertinentes y los medios didácticos adecuados. El cómo lograr estos objetivos es tarea de la educación.

Puesto que ya se ha concebido y trazado la educación desde esta propuesta, es menester averiguar que está sucediendo al interior del hecho educativo, puesto que los logros en no pocos casos son desalentadores. 
La reflexión filosófica, en torno a los temas de ética y educación, debe desarrollarse hoy más que nunca, para des-encubrir las sesgadas intenciones desde las cuales se construye la educación. Actualmente se da una amplia gama de propuestas éticas y educativas, que terminan quitando significado al valor de la persona humana. De valor central y fin en sí mismo, la persona ha terminado sin su real valoración y se ha convertido en un medio más de los intereses de nuestro inhumano sistema capitalista; tanto así, que hasta en la misma educación, la personas que pretenden educarse, son vistas como oportunidades para lograr beneficios económicos.

No se debe perder de vista el indicador central desde el cual se ha planteado el fundamento ético de la educación: la persona humana. Toda intencionalidad educativa, si no es según la ética que se ha planteado, corre la suerte de ser cualquier proyecto exitoso, menos educación. Los diversos tipos de calidad educativa, incluso los paradigmas pedagógicos que de cuando en cuando aparecen, deben ser aquilatados desde el valor, tan antiguo y siempre nuevo, de la persona humana.

\section{Notas}

1 La denominación Persona Humana se refiere a esa caracterización fundamental del ser humano a nivel fenomenológico, existencial y personalista.

2 No se debe pensar que antes del siglo XX no existiera el "valor", sino porque anteriormente no había la conciencia del mismo como tal. En ese tiempo anterior se lo conocía como bien.

3 Idea tomada en una clase de Axiología dirigida por el P. Alejandro Saavedra, sdb. 


\section{Bibliografía}

GASTALDI, Ítalo

1994 El Hombre un Misterio. Quito, Ecuador: Ediciones Don Bosco.

MACEIRAS, Manuel

2001 Para Comprender la Filosofía como Reflexión Hoy.

Navarra, España: Editorial Verbo Divino.

SAAVEDRA, Alejandro

2005 Formación de la Conciencia en Valores. Lima, Perú. 